\title{
KAPABILITAS PROSES PACKING SEMEN \\ DENGAN MENGGUNAKAN STATISTIKAL QUALITY CONTROL (STUDI KASUS: PT. SEMEN BOSOWA MAROS)
}

\author{
Irwan*, Try Azisah Nurman, Risna Sukardi \\ Jurusan Matematika \\ Fakultas Sains dan Teknologi UIN Alauddin Makassar \\ Jl. Sultan Alauddin No. 63, Kabupaten Gowa, Sulawesi Selatan. 92113 \\ *E-mail: irwan.msi@uin-alauddin.ac.id
}

\begin{abstract}
Abstrak: Penelitian ini membahas kemampuan proses pengepakan semen. Tujuannya untuk mengetahui apakah kemasan produk semen sudah sesuai dengan spesifikasi atau belum. Pendekatan yang digunakan adalah pengendalian mutu secara statistik dengan teknik analisis data yang digunakan yaitu peta kendali P. Hasil analisis statistik dengan SQC periode 15 Juli-31 Agustus secara statistik tidak terkendali dan hasil pengemasan tidak sesuai dengan spesifikasi atau dengan kata lain proses pengemasan tidak sesuai dengan standar. Faktor-faktor yang menjadi penyebab utama adalah penggunaan kemasan yang berbeda.
\end{abstract}

Kata Kunci: kapabilitas, kemasan semen, peta kendali P, Statistical Quality Control (SQC),

\section{PENDAHULUAN}

danya pengendalian kualitas yang baik pada suatu perusahaan dapat meningkatkan kebaikan produk serta keuntungan pada perusaahaan dan dapat 1 meminimalisir kecacatan atau kerusakan yang terjadi. Adapun cara atau metode yang dapat digunakan dalam melihat kualitas dari suatu produk yaitu menggunakan metode Statistical Quality Control (SQC). PT. Semen Bosowa merupakan PT yang memproduksi semen. Berdasarkan data yang diperoleh setiap harinya oleh pekerja pengemasan, proses pengemasan semen banyak terjadi kegagalan (reject). Jika terjadi produk gagal maka semen yang tadinya rusak harus di kembalikan karena kertas kemasan yang digunakan menjadi rusak dan juga menyita waktu lebih lama karena harus dilakukan mengemasan ulang. Karena hal tersebut maka dilakukanlah kapabilitas kualitas dengan menggunakan peta kendali $\mathrm{P}$ untuk mengetahui apakah selama proses produksi, produk yang dihasilkan sudah memenuhi spesifikasi dan meminimalisir kerugian perusahaan.

Kapabilitas adalah suatu teknik pengendalian kualitas yang bertujuan untuk menaksir kemampuan dari suatu proses produksi. Dalam proses analisis kapabilitas harus dilakukan pengendalian kualitas secara statistik. Ada banyak penelitian yang menggunakan SQC dan menentukan nilai kapabilitas proses dalam penelitian di antaranya yaitu penelitian yang dilakukan oleh Wardhana et al. (2018) diperoleh hasil analisis Statistical Quality Control (SQC) dengan peta kendali X dan R menunjukkan jumlah sampel di luar batas kendali. Penelitian yang dilakukan oleh Hairiyah et al. (2019) dan Rujianto \& Wahyuni (2018) sama-sama menggunakan metode SQC untuk menganalisis faktor-faktor yang memengaruhi produksi roti di Aremania Bakery. Data yang diperoleh dengan analisis peta kendali menunjukkan bahwa pengendalian mutu masih di luar batas kendali, dan terdapat 4 faktor yang memengaruhi terjadinya reject 
antara lain: manusia, metode, mesin, dan material. Pengukuran kinerja karyawan dengan menggunakan HRA, menunjukkan bahwa faktor terbesar diakibatkan oleh manusia (Bakhtiar et al., 2013). Bakhtiar et al. (2013), Khikmawati et al. (2019) serta Krisdayanti \& Moektiwibowo (2016), sama-sama menggunakan SQC untuk menganalisis faktorfaktor yang memengaruhi penyimpangan kualitas dari sekian kerusakan yang terjadi. Faktor yang paling berpengaruh adalah kerusakan pada botol, yaitu pecah dan retak yang disebabkan oleh 4 faktor yaitu manusia, material, metode dan hasil penelitiannya yaitu faktor penyebab kerusakan komponen berasal dari faktor manusia dan metode kerja.

Wibowo et al. (2019) memperoleh hasil penelitian yang menunjukkan bahwa dengan penggunaan peta kendali variabel masih terdapat data yang berada di luar batas kendali, dan setelah dilakukan revisi seluruh data sudah berada dalam batas kendali. Sedangkan dari hasil penelitian Elmas (2017) diperoleh hasil bahwa yang menunjukkan bahwa tingkat kerusakan produk masih dalam batas wajar. Hamdani \& Fakhriza (2019) dengan hasil penelitian yaitu kontrol kualitas pada produk poros bertingkat baik karena jumlah produk yang menyimpang masih dalam batas-batas wajar yaitu hanya 2-3 bagian ukuran pada sampel. Sedangkan hasil dari diagram fishbone (tulang ikan) menunjukkan bahwa faktor utama penyebab penyimpangan ukuran poros bertingkat yaitu ada pada manusia.

Riani Puspa Sari \& Puspita (2018) dengan hasil penelitian yaitu Assy Parking Brake saat proses produksi dengan menggunakan metode Statistical Quality Control (SQC) bahwa dari 22 data proses produksi terdapat 13 data proses produksi yang berada di luar batas pengendalian yang dihasilkan pada bulan Maret 2018 sebesar 59\% sedangkan data proses produksi yang berada dalam batas pengendalian sebanyak 9 data proses produksi atau sebesar $41 \%$. Lestari \& Rahmat (2018) dengan hasil penelitian yaitu keempat jenis roti yang menjadi objek penelitian masih dalam batas standar perusahaan. Haryani \& Linda (2019) memperoleh hasil penelitian dengan menggunakan analisis Statistical Quality Control (SQC) yaitu bahwa terlihat nilai kecacatan produk masih sangat tinggi yaitu sebesar 3,193\% dan dengan menggunakan diagram kendali P (P-Chart) juga terlihat bahwa masih terdapat proporsi kecacatan yang berada di luar batas kendali. Dengan demikian pengendalian dan kerusakan pada Liberty Shoes masih belum stabil. Berdasarkan penelitian yang dilakukan oleh Krisdayanti \& Moektiwibowo (2016) dapat diketahui bahwa faktor penyebab kerusakan komponen berasal dari faktor manusia dan metode kerja, sehingga perusahaan dapat mengambil tindakan pencegahan serta perbaikan untuk menekan tingkat kerusakan dan meningkatkan kualitas komponen.

Peta kendali menggambarkan perbaikan kualitas. Peta kendali yang menunjukkan keadaan tak terkendali (tidak terkontrol) apabila satu atau lebih titik yang berada di luar batas pengendali. Peta kendali atribut merupakan peta kendali yang digunakan untuk mengukur kualitas dari ketidaksesuaian produk dengan tujuan untuk mengetahui apakah produksi tersebut berada dalam kondisi terkontrol (in statistical control) ataukah tidak terkontrol (out of statistical control).

Peta kendali $\mathrm{P}$ adalah salah satu peta kendali atribut yang digunakan untuk mengontrol bagian produk cacat dari produksi. Kontrol proporsi kesalahan (p-chart) digunakan untuk mengetahui apakah cacat produk yang dihasilkan masih dalam batas yang diperlukan atau tidak. Adapun pembuatan peta kendali P dilakukan dengan tahapan yaitu:

1. Menghitung persentase ketidaksesuaian dengan rumus $\mathrm{p}=(\mathrm{n} . \mathrm{p}) / \mathrm{n}$;

2. Menghitung garis pusat/central line (CL) dengan rumus $C L=\bar{p}=\frac{\sum n \cdot p}{\sum n}$; 
3. Menghitung batas kendali atas(UCL) dengan rumus $U C L=\bar{p}+3 \sqrt{\frac{\bar{p}(1-\bar{p})}{n}}$;

4. Menghitung batas kendali bawah (LCL) dengan rumus $L C L=\bar{p}-3 \sqrt{\frac{\bar{p}(1-\bar{p})}{n}}$.

Quality Control atau pengendalian kualitas adalah kombinasi semua alat dan teknik yang digunakan untuk mengontrol kualitas suatu produk dengan biaya seekonomis mungkin dan memenuhi syarat pemesan (Wardhana et al., 2018). Tujuan pokok pengendalian kualitas statistik adalah menyidik dengan cepat terjadinya sebab-sebab terduga atau pergeseran proses sedemikian hingga penyelidikan terhadap proses itu dan tindakan pembetulan dapat dilakukan sebelum terlalu banyak unit yang tidak sesuai diproduksi. Diagram pareto merupakan proses dalam membuat peringkat untuk membandingkan berbagai klasifikasi atau kategori kejadian yang disusun menurut ukurannya (Elmas, 2017). Dalam penelitian digunakan diagram sebab akibat (Fishbone Diagram) yang merupakan diagram yang menggambarkan hubungan antara karakteristik mutu dengan faktor penyebabnya.

Analisis kapabilitas proses (Process Capability Analysis) adalah suatu studi teknik menaksir kapabilitas proses. Ada 3 proses yang harus dilakukan dalam menentukan kapabilitas yaitu:

1. Menghitung nilai Cp (Potential Capability Index) dengan rumus $C_{p}=\frac{U S L-L S L}{6 \sigma}$.

2. Menghitung nilai $\mathrm{Cpk}$ (Real Capability Index) dengan rumus $C_{p k}=$ $\min \left(C_{p u}, C_{p l}\right)$ dimana $C_{p u}=\frac{U S L-\mu}{3 \sigma}$ dan $C_{p l}=\frac{\mu-L S L}{3 \sigma}$.

3. Menghitung nilai Cpm (Mean Capability Index) dengan rumus $C_{p m}=\frac{U S L-L S L}{6 \tau}$.

Berdasarkan Hairiyah et al. (2019), untuk menentukan nilai Confidence Interval (IC) yaitu dengan cara sebagai berikut:

1. Menetukan CI untuk Cp

2. Menentukan nilai CI untuk $\mathrm{Cpk}$

$$
\left(\hat{C}_{p} \sqrt{\frac{\chi_{1-\frac{\alpha}{2}, n-1}^{2}}{n-1}} \leq C_{p} \leq \hat{C}_{p} \sqrt{\frac{\chi_{\frac{\alpha}{2}, n-1}^{2}}{n-1}}\right) .
$$

$$
\hat{C}_{p k}\left[1-Z_{\alpha / 2} \sqrt{\frac{1}{9 n \hat{C}_{p k}^{2}}+\frac{1}{2(n-1)}}\right] \leq C_{p k} \leq \hat{C}_{p k}\left[1+Z_{\alpha / 2} \sqrt{\frac{1}{9 n \hat{C}_{p k}^{2}}+\frac{1}{2(n-1)}}\right] .
$$

3. Menentukan nilai CI untuk $\mathrm{Cpm}$

$$
\frac{\hat{C}_{p m}}{\sqrt{\frac{n-1}{\chi_{\frac{\alpha}{2} ; n}^{2}}}} \leq C_{p m} \leq \frac{\hat{C}_{p m}}{\sqrt{\frac{n-1}{\chi_{1-\frac{\alpha}{2} ; n}^{2}}}} .
$$

\section{METODE PENELITIAN}

Jenis penelitian yang digunakan dalam penelitian ini adalah penelitian terapan. Jenis data dan sumber data dalam penelitian ini adalah data sekunder yang diambil langsung dari instansi yang bersangkutan yaitu PT. Semen Bosowa Maros. Penelitian ini dilakukan di PT. Semen Bosowa Maros Desa Siawung Kabupaten Barru mulai dari Oktober 2019-Agustus 2020. Metode yang digunakan pada perancangan penataan kawasan ini antara lain:

1. Mengambil data pada perusahaan PT. Semen Bosowa Maros;

2. Melakukan analisis deskriptif pada data;

3. Analisis kecacatan proses pengemasan semen berdasarkan mesin yang digunakan menggunakan diagram pareto; 
4. Menghitung dengan menggunakan peta kendali $P$ untuk mengetahui apakah data sudah terkendali atau tidak dilakukan dengan langkah-langkah sebagai berikut:
a. Menghitung Garis Pusat/Center Line (CL)
b. Menghitung Batas Kendali Atas/Upper Control Line (UCL)
c. Menghitung Batas Kendali Bawah/Lower Control Line (LCL)
d. Menggambar grafik pengendalian kualitas statistik.

5. Merevisi garis tengah dan batas pengendalian apabila dalam grafik pengendalian kualitas statistik jika terdapat data yang berbeda di luar batas pengendalian statistik dengan langkah-langkah sebagai berikut:
a. Menghitung Garis Pusat/Center Line (CL)
b. Menghitung Batas Kendali Atas/Upper Control Line (UCL)
c. Menghitung Batas Kendali Bawah/Lower Control Line (LCL)
d. Menggambar grafik pengendalian kualitas statistik

6. Menghitung nilai kapabilitas proses pengemasan semen pada PT. Semen Bosowa Maros dengan langkah-langkah sebagai berikut:
a. Menghitung nilai Cp (Potential Capability Index)
b. Menghitung nilai Cpk (Real Capability Index)
c. Menghitung nilai Cpm (Mean Capability Index)

7. Menghitung nilai Confidance Interval (CI)

8. Membuat diagram sebab akibat untuk mengetahui penyebab adanya produk yang berada di luar batas kendali.

\section{HASIL DAN PEMBAHASAN}

Nilai rata-rata jumlah cacat hasil produksi adalah sebesar 57, jumlah cacat terbesar 912, jumlah cacat terkecil 2, standar deviasi yaitu 0.0455 , dan variansinya sebesar 0.00207025 (Tabel 1).

Tabel 1. Statistika deskriptif data jumlah cacat proses packing semen

\begin{tabular}{llllll}
\hline Jumlah Cacat & Mean & Max & Min & Sd & Var \\
\hline 912 & 57 & 912 & 2 & 0,0455 & 0.00207025
\end{tabular}

Analisis kecacatan proses pengemasan semen berdasarkan mesin yang digunakan menggunakan diagram pareto poisson. Berdasarkan diagram pareto (Gambar 1) diketahui kecacatan yang paling sering terjadi yaitu reject pada saat mesin 2 sebesar 612 yaitu sebesar 67.

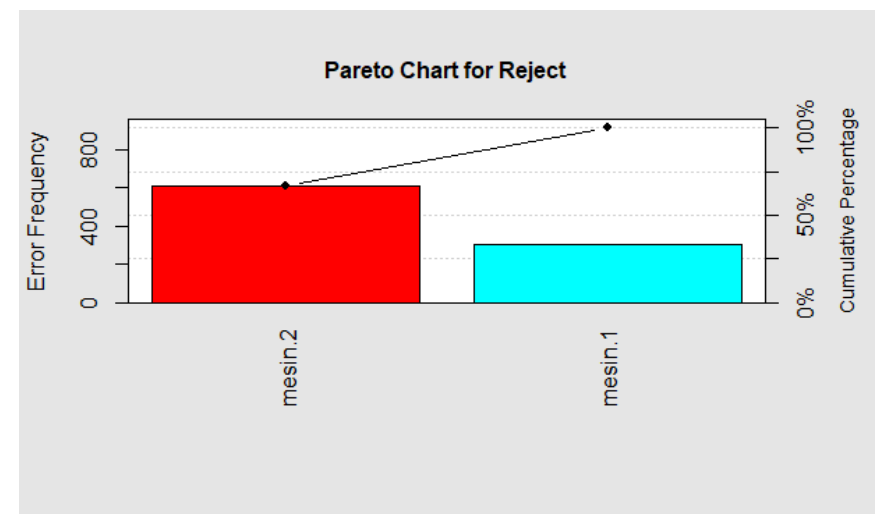

Gambar 1. Diagram pareto poission 


\section{Peta Kendali P Pada Proses Pengemasan Semen}

Perhitungan Garis Pusat/Center Line (CP), berdasarkan hasil perhitungan didapatkan $\mathrm{p}=0,002077671$. Proporsi untuk observasi pertama sampai pada observasi ke 31 dapat dilihat pada Tabel 2.

Tabel 2. Proporsi observasi pertama pada data

\begin{tabular}{llll}
\hline Observasi & Total Produksi & Jumlah Cacat & Proporsi \\
\hline $\mathbf{1}$ & 11031 & 27 & 0,002448 \\
\hline $\mathbf{2}$ & 20638 & 39 & 0,001889 \\
\hline $\mathbf{3}$ & 7286 & 28 & 0,003843 \\
\hline $\boldsymbol{*}$ & $\cdot$ & $\cdot$ & $\cdot$ \\
\hline $\boldsymbol{B}$ & $\cdot$ & $\cdot$ & $\cdot$ \\
\hline $\mathbf{3 1}$ & $\cdot$ & $\cdot$ & $\cdot$ \\
\hline
\end{tabular}

Batas kendali untuk observasi pertama dengan jumlah sampel 11031 sak adalah sebagai berikut:

$$
\begin{gathered}
U C L=0,002077+3 \sqrt{\frac{(0,002077)(1-0,002077)}{11031}}=0,003378292, \\
L C L=0,002077-3 \sqrt{\frac{(0,002077)(1-0,002077)}{11031}}=0,0007771 .
\end{gathered}
$$

Batas kendali untuk observasi kedua dengan jumlah sampel 20638 sak adalah sebagai berikut:

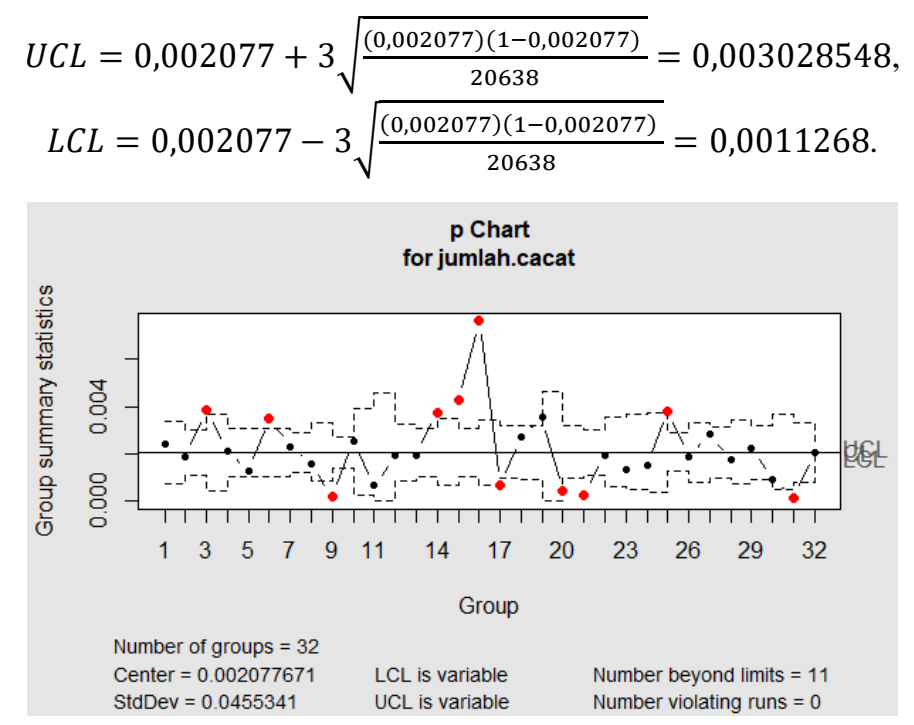

Gambar 2. Peta kendali P proses pengemasan semen pada bulan Agustus

Berdasarkan Gambar 2 menunjukkan ada beberapa titik-titik yang berada di luar batas kendali yang menunjukkan penyimpangan walaupun tidak signifikan. Sehingga dilakukan pemeriksaan terhadap garis tengah dan batas pengendali yang dihitung menggunakan titik-titik yang tersisa. Untuk revisi pertama, titik-titik yang berda di luar batas kendali dihilangkan. Total observasi yaitu 31 titik dikurangi dengan titik-titik yang di luar batas kendali yaitu 11 titik. 


\section{Perhitungan Revisi 1}

Nilai pada Center Line $\bar{p}$ dihitung menggunakan rumus $\bar{p}=\frac{\sum n \cdot p}{\sum n}, i=1,2,3, \ldots, 20$ sehingga diperoleh $\bar{p}=0,00202$.

Tabel 3. Proporsi observasi data pada revisi 1

\begin{tabular}{cccl}
\hline Observasi & Total Produksi & Jumlah Cacat & Proporsi \\
\hline $\mathbf{1}$ & 11031 & 27 & 0,002448 \\
\hline $\mathbf{2}$ & 20638 & 39 & 0,00189 \\
\hline $\mathbf{4}$ & 18120 & 39 & 0,002152 \\
\hline $\boldsymbol{*}$ & $\cdot$ & $\cdot$ & $\cdot$ \\
\hline$\cdot$ & $\cdot$ & $\cdot$ &. \\
\hline $\boldsymbol{3 0}$ & $\cdot$ & $\cdot$ & $\cdot$ \\
\hline
\end{tabular}

Batas kendali untuk observasi pertama dengan jumlah sampel 11031 sak adalah sebagai berikut:

$$
\begin{aligned}
& U C L=0,00202+3 \sqrt{\frac{(0,00202)(1-0,00202)}{11031}}=0,003304647, \\
& L C L=0,00202-3 \sqrt{\frac{(0,00202)(1-0,00202)}{11031}}=0,000738645 .
\end{aligned}
$$

Batas kendali untuk observasi kedua dengan jumlah sampel 20638 sak adalah sebagai berikut:

$$
\begin{aligned}
& U C L=0,00202+3 \sqrt{\frac{(0,00202)(1-0,00202)}{20638}}=0,002959641, \\
& U C L=0,00202+3 \sqrt{\frac{(0,00202)(1-0,00202)}{20638}}=0,001083651 .
\end{aligned}
$$

Hasil perhitungan tersebut dapat dilihat pada Gambar 3.

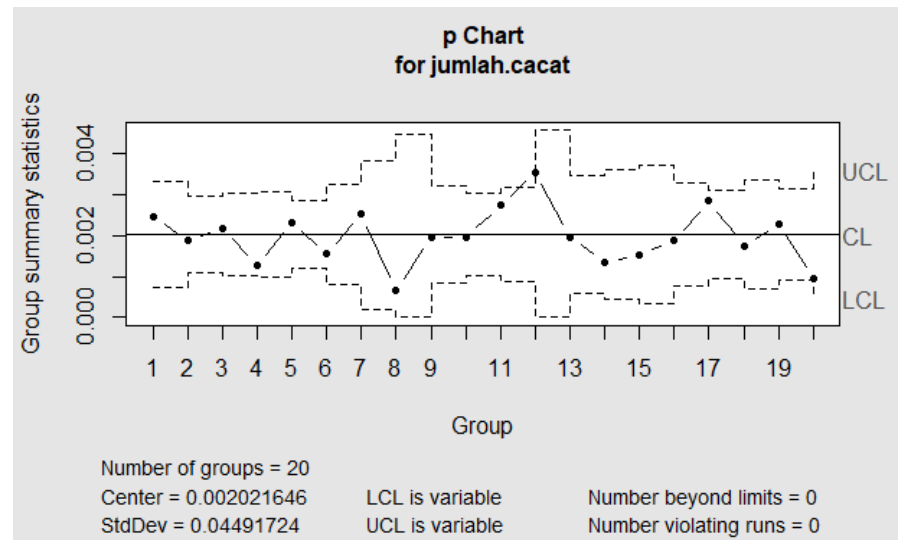

Gambar 3. Peta kendali p revisi 1

Pada Gambar 3, peta kendali p hasil proporsi kecacatan CL, UCL, dan LCL terlihat bahwa tidak ada lagi titik yang berada di luar batas pengendali atas maupun bawah. Hal ini mengindikasikan bahwa analisis proses packing semen di PT. Semen Bosowa Maros sudah berada dalam batas pengendali statistik dengan melakukan 1 kali revisi. Dengan 
kondisi seperti ini dapat digunakan sebagai acuan perencanaan pengendalian kualitas statistik tahun berikutnya.

\section{Nilai Kapabilitas Proses}

a. Nilai $C_{p}$ (Potential Capability Index)

$$
C_{p}=\frac{U C L-L C L}{6 \sigma} .
$$

Maka, diperoleh nilai $C_{p}=0,1793868745$.

b. Nilai $C_{p k}$ (Real Capability Index)

$$
\begin{gathered}
C_{p k}=\min \left(C_{p u}, C_{p l}\right), \\
=\min (0,179320392,0,17941899=\min (0,179320392) .
\end{gathered}
$$

c. Nilai Menghitung nilai $C_{p m}$ (Mean Capability Index)

$$
\begin{gathered}
C_{p m}=\frac{U C L-L C L}{6 \tau}, \\
=\frac{0.003393041-0.000646204}{6(0.0025525932)} \\
=0.1793494422 .
\end{gathered}
$$

Berdasarkan hasil perhitungan, diperoleh nilai $C p=0,1793868745$ dimana nilai $0,1793868745<1$ artinya bahwa proses tersebut menghasilkan produk yang tidak sesuai dengan spesifikasi atau dengan kata lain proses non capable. Selanjutnya diperoleh nilai $C p k=0,1794189958$, dimana nilai $0,1794189958<1,33$ maka menujukan bahwa proses menghasilkan produk yang tidak sesuai dengan spesifikasi.

\section{Nilai CI (Convidence Interval)}

a. Nilai $C I$ (Convidence Interv bal) untuk $C_{p}$ (Potential Capability Index)

$$
\begin{gathered}
\left(\hat{C}_{p} \sqrt{\frac{\chi_{1-\frac{\alpha}{2}, n-1}^{2}}{n-1}} \leq C_{p} \leq \hat{C}_{p} \sqrt{\frac{\chi_{\frac{\alpha}{2}, n-1}^{2}}{n-1}}\right), \\
\left(0,1342009262 \leq C_{p} \leq 0.2244845943\right) .
\end{gathered}
$$

b. Nilai CI (Convidence Interval) untuk Cpk (Real Capability Index)

$$
\begin{gathered}
\hat{C}_{p k}\left[1-Z_{\alpha / 2} \sqrt{\frac{1}{9 n \hat{C}_{p k}^{2}}+\frac{1}{2(n-1)}}\right] \leq C_{p k} \leq \hat{C}_{p k}\left[1+Z_{\alpha / 2} \sqrt{\frac{1}{9 n \hat{C}_{p k}^{2}}+\frac{1}{2(n-1)}}\right], \\
0.0534899454 \leq C_{p k} \leq 0.30514 .
\end{gathered}
$$

c. Nilai CI (Convidence Interval) untuk $C_{p m}$ (Mean Capability Index)

$$
\begin{array}{r}
\frac{\hat{C}_{p m}}{\sqrt{\frac{n-1}{\chi_{\frac{\alpha}{2}}^{2}}}} \leq C_{p m} \leq \frac{\hat{C}_{p m}}{\sqrt{\frac{n-1}{\chi_{1-\frac{\alpha}{2} ; n}^{2}}}} \\
0.2244379 \leq C_{p m} \leq 0.134168 .
\end{array}
$$

Berdasarkan nilai $C I$ yang diperoleh pada $C_{p}, C_{p k}, C_{p m}$ pada kapabilitas masingmasing adalah 0,1793868745, 0,179320392, dan 0.1793494422. Dengan menggunakan nilai $C I$ dapat membantu peneliti untuk mengetahui apakah nilai yang 
diperoleh sudah tepat berada di interval nilai yang diperoleh. Berdasarkan hasil yang diperoleh, nilainya sudah sesuai dan berada pada interval yang diperoleh.

\section{KESIMPULAN}

Berdasarkan data setelah dilakukan penelitian menggunakan peta kendali $\mathrm{p}$ (control $p$ chart) diperoleh hasil yang menunjukkan bahwa data belum terkendali secara statistik sehingga dilakukan penelitian lebih lanjut agar data berada dalam batas kendali dengan cara merevisi data dan berdasarkan nilai $C_{p}=0,1793868745$, nilai $0,1793868745<1$ artinya bahwa proses tersebut menghasilkan produk yang tidak sesuai dengan spesifikasi atau dengan kata lain proses non capable. Selanjutnya diperoleh nilai $C_{p k}=0,1794189958$, nilai $0,1794189958<1,33$ maka menunjukan bahwa proses menghasilkan produk yang tidak sesuai dengan spesifikasi. Maka dapat dikatakan bahwa kapabilitas proses pada mesin 1 dan mesin 2 belum kapabel atau belum memenuhi spesifikasi.

\section{DAFTAR PUSTAKA}

Yani, A. S. (2018). Analisis pengawasan kualitas produk dengan menggunakan metode p-charts untuk meminimalkan tingkat kerusakan produk pada UKM sepatu. Journal for Business and Entrepreneur, 2(1), 54-64.

Bakhtiar, S., S. Tahir., \& R. A. Hasni. (2013). Analisis pengendalian kualitas dengan menggunakan metode statistical quality control (SQC). MIEJ Journal, 2(1), 29-36.

Montogomery, D. C. (2001). Introduction to statistikal quality control. (4th ed.) New Jersey: Wiley.

Montogomery, D. C. (2008). Introduction to Statistikal Quality Control. ( ${ }^{\text {th }}$ ed.). New Jersey: Wiley.

Khikmawati, E., H. Wibowao., \& I. Irwansyah. (2019). Analisis pengendalian kualitas kemasan glukosa dengan peta kendali P di PT. Budi Starch \& Sweetener TBK. Lampung Tengah. Jurnal UNTAR, 7(1), 27-33. Doi. 10.24912/jitiuntar.v7i1.5031.

Hamdani, H., \& F. Fakhriza (2019). Pengendalian kualitas pada hasil pembubutan dengan menggunakan metode SQC. Jurnal Rekayasa Material, Manufaktur dan Energi, 2(1), 1-9. Doi. 10.30596/rmme.v2i1.3063.

Wibowo, H., E. Khikmawati., \& M. Sagala. (2019). Analisis statistical quality control bahan olahan karet (bokar) jenis Sir 20 dengan pendekatan peta kendali variabel. Jurnal Semdi Unaya, 3(1).

Haryani, I., \& M. R. Linda. (2019). Penerapan pengendalian mutu produksi dengan statistical quality control (SQC) dan six sigma pada Liberty Shoes Kota Padang. Jurnal Creative Commons, 1(2), 2433.

Irwan \& D. Haryono. (2015). Pengendalian kualitas statistik (Pendekatan teoritis dan praktis). Bandung: Alfabeta).

Rujianto, K., \& H. C. Wahyuni. (2018). Pengendalian kualitas produk dengan menggunakan metode SQC dan HRA guna meningkatkan hasil produksi tahu di IKM H. Musauwimin. Jurnal Prozima, 2(1), 111.

Kurniati. (2018). Analisis Pengendalian Kualitas dengan Statistical Quality Control Guna Mengurangi Tingkat Kecacatan Proses Packaging (Studi Kasus: PT. Makassar Tene) [Skripsi]. Makassar: Universitas Islam Negeri Alauddin Makassar.

Angraeni, L. L. (2017). Analisis Kapabilitas Proses Pengemasan Minyak Goreng di PT. Salim Ivomas Pratama Tbk Surabaya [Skripsi]. Surabaya: Institut Teknologi Sepuluh Nopember Surabaya.

Wardhana, M. W., S. Sulastri., \& E. A. Kurniawan. (2018). Analisis peta kendali variabel pada pengolahan produk minyak sawit dengan pendekatan statistical quality control (SQC). Jurnal Rekayasa Teknologi dan Sains, 2(1), 27-34.

Elmas, M. S. H. (2017). Pengendalian kualitas dengan menggunakan metode statistical quality control (SQC) untuk meminimumkan produk gagal pada Toko Roti Barokah Bakery. Jurnal Penelitian dan Ilmu Ekonomi WIGA, 7(1), 15-22.

Hairiyah, N., R. R. Amalia., \& E. Luliyanti. (2019). Analisis statistical quality control (SQC) pada Produksi roti di Aremania Bakery. Jurnal Teknologi dan Manajemen Agroindustri, 8(1), 41-48.

Sari, R. P., \& D. Puspita. (2018). Analisis tingkat kecacatan produk lever assy parking brake menggunakan metode statistical quality control (SQC). Jurnal of Industrial Engineering and Management Systems, 11(2), 77-83. Doi. 10.30813/jiems.v11i2.1184. 
66_Jurnal Teknosains, Volume 15, Nomor 1, Januari-April 2021, hlm. 58-66

Krisdayanti, S., \& H. Moektiwibowo. (2016). Pengendalian kualitas komponen mobil dengan metode SQC (statistical quality control). Jurnal Teknik Industri, 5(1), 9-20.

Lestari, T. E., \& N. S. Rahmat. (2018). Analisis of quality control using statistical process control (SPC) in bread production. Indonesian Journal of Fundamental Sciences, 4(2), 90-101. 